\title{
Emergency Department presentation of frail older people and interventions for management: Geriatric Emergency Department Intervention
}

\author{
Alison Craswell ${ }^{1 *} \mathbb{D}$, Elizabeth Marsden ${ }^{2}$, Andrea Taylor ${ }^{2}$ and Marianne Wallis ${ }^{1}$
}

\begin{abstract}
As population's age and people live longer, the burden on acute health care services associated with the frail aged increases. Recognising the needs of this cohort as well as designing and evaluating interventions to manage their care in the emergency department has been reported in the literature. Transition to new models of care in emergency departments (ED) focused on improving the care of older people can also assist in reducing length of stay in the ED, reducing complications associated with ED presentation and prevent inappropriate hospitalisation. The Geriatric Emergency Department Intervention (GEDI) aims to build on the successful components of other models of care for older people in acute healthcare settings to improve safety and best meet the needs of both older people and health service providers.
\end{abstract}

Keywords: Advanced practice nurse, Emergency department collaboration, Geriatric, Aged care, Hospital avoidance, Older people

\section{Background}

In the developed world, the proportion of the populations of people aged 65 years and over are increasing at a disproportionate rate, compared to other age groups, resulting in an increased burden on health systems as a consequence of the chronic disease and frailty experienced by this cohort [1]. Emergency departments (ED) are increasingly being accessed by older people from both the community and residential aged care facilities (RACF) to either meet shortfalls in access to primary care or when usual primary care is disrupted [2,3]. Reasons for presentation to the ED by older people for low acuity conditions are reported to be influenced by perceived urgency, difficulty accessing primary healthcare, referral to ED from Primary Healthcare Physician (PHP) [3, 4] and staffing in RACFs [5-7]. The presence of chronic comorbidities such as chronic airways disease, congestive cardiac failure, and diabetes in addition to other functional

\footnotetext{
* Correspondence: acraswel@usc.edu.au

${ }^{1}$ University of the Sunshine Coast, 90 Sippy Downs Drive, Sippy Downs, Qld

4556, Australia

Full list of author information is available at the end of the article
}

considerations such as the presence of indwelling devices and absence of an Advance Care Plan were reported as risk factors for transfer to the ED [8].

Evidence of the efficacy of health service interventions aimed at providing appropriate care for ageing populations is present in the literature with varying levels of success reported [9-18]. Some examples of these interventions are: improving care in RACFs via change in staffing models most often to include a Nurse Practitioner [11], interventions in EDs for presentation of older people, and outreach models from health services to the community most often provided by nurses, hospital in the home (HITH) and hospital in the nursing home (HINH). Interventions within RACFs found to be successful in improving care of residents include use of gerontology specific clinical pathways, improved communication with primary pracitioners and promotion of Advance Care Planning (ACP) [10]. Evidence for successful, ED specific interventions in improving care for older people who present to the ED, focuses on supported discharge, senior medical review, comprehensive geriatric assessment $[15,19]$ and staff education in 
geriatric specific emergency medicine [17]. Attention to the design of a specific area in the ED to introduce natural lighting and noise reduction in an effort to be more 'older people friendly', similar to such areas for pediatrics, is increasing in popularity [17]. There is some evidence that outreach interventions such as HiTH and Hospital in the Nursing Home (HINH) as exemplars for supported early discharge also result in decreased admission rates from RACFs to EDs and reduced length of stay if admitted [13, 20, 21].

Changes in policy in Australia in 2010 to introduce a four hour National Emergecy Access Target (NEAT) for care of patients in the ED [22] in conjuunction with increasing numbers of presentations to the ED from older people from the community and RACFs has increased pressure on EDs. Residents from RACFs are reported to expereince extended ED stays and elevated levels of admission to hospital compared to other cohorts [23, 24]. Older people who present to the ED are triaged at a higher rate into Category 3 and Category 4 on the Australasian Triage Scale [23, 25], compared to their younger counterparts.

Staff in EDs are generally not highly skilled in the care of older people who generally suffer exacerbations of chronic illness with multiple comorbidities. This is reported to result in misdiagnosis of older people by ED staff [26]. These factors and a need to reduce length of stay in the ED and inappropriate admissions of older people have led to the development of an initiative to provide specialist care for older people presenting to the ED in a regional Hospital and Health Service in Queensland, Australia. The aim of this commentary is to define this innnovation, the Geriatric Emergency Department Intervention (GEDI), present evidence underpinning the assessment methods used by GEDI and outline the similarities and differences between GEDI and other ED models of care for the frail older person.

\section{GEDI intervention}

The GEDI intervention is delivered in the ED by a multidisciplinary team consisting of a dedicated ED physician and advanced practice nurses who have additional experience and education in gerontology and care of frail, older people. The GEDI nurses work with the primary care ED nurses and ED physicians providing targeted geriatric assessment, multi-disciplinary decision-making and coordination of care for these more complex patients. Critical to the integration of GEDI into the ED is the role the physician plays in driving acceptance, policy change, and clinical support to overcome barriers to implementation. Advance practice nurses, including a Clinical Nurse Consultant, utilise community services to best meet the needs of presenting older people from either the community or RACFs, who can benefit from transition back to place of residence from the ED. These GEDI nurses are available 7 days a week in ED and act in a consultant capacity providing a brief review of all people over 70 years of age presenting to the department. Based on this brief review, targeted geriatric assessment helps determine those who will benefit from rapid assessment and management of their concern in ED with the intent of returning them home either to the community or RACF as soon as practical. The aim of the rapid turnaround is to prevent the potential for complications that often result from presentation to the ED occurring in frail older people [4, 10, 27].

The GEDI team gather assessment information related not only to the presenting condition, but also to the extent of functional decline, cognitive deterioration and overall frailty of older persons presenting to the ED. This in turn informs clinical decision making and allows for the assessment of the level of service required to support safe discharge. An outline showing how the GEDI service interacts with other health professionals and services for liaison and referral can be seen in Fig. 1.

The GEDI team representxs a dedicated single point of contact for RACF staff and PHPs referring older people to the ED. They liaise with the older person, their family and/or carer, ED physicians and Gerontologists and specialist medical consultants along with the PHP and other relevant primary care professionals. Discharge summaries to the RACF and PHP provide communication of the care episode and details of all referrals. Improved communication between healthcare services, PHP and community services aims to build on Safety-II principals [28], concentrating on what succeeds in the ongoing care of the older person. The GEDI team also facilitates direct admission pathways to orthopaedic surgery and other specialties where appropriate. Finally, education and upskilling of ED staff is provided to assist in increasing the expertise of all ED staff to provide appropriate care for this cohort. Research evaluation of the GEDI model is currently in progress.

\section{Evidence for GEDI intervention}

The GEDI intervention was built on evidence from successful aspects of existing models of care in hospitals and EDs in the care of older adults suffering acute episodes of decline in their health. Comprehensive Geriatric Assessment (CGA) of older adults has been shown to result in longevity and independence, less likelihood of requiring admission to a RACF, reduced deterioration and improvement in cognition [29]. However, it is not clearly defined how much comprehensive geriatric assessment should be carried out in the ED. Completing a CGA in the ED has limitations due to the length of time required to accomplish the assessment and the skills required of the health practitioner to adequately complete the assessment [30]. GEDI nurses screen older people presenting to the ED to identify those who can benefit from a targeted geriatric 


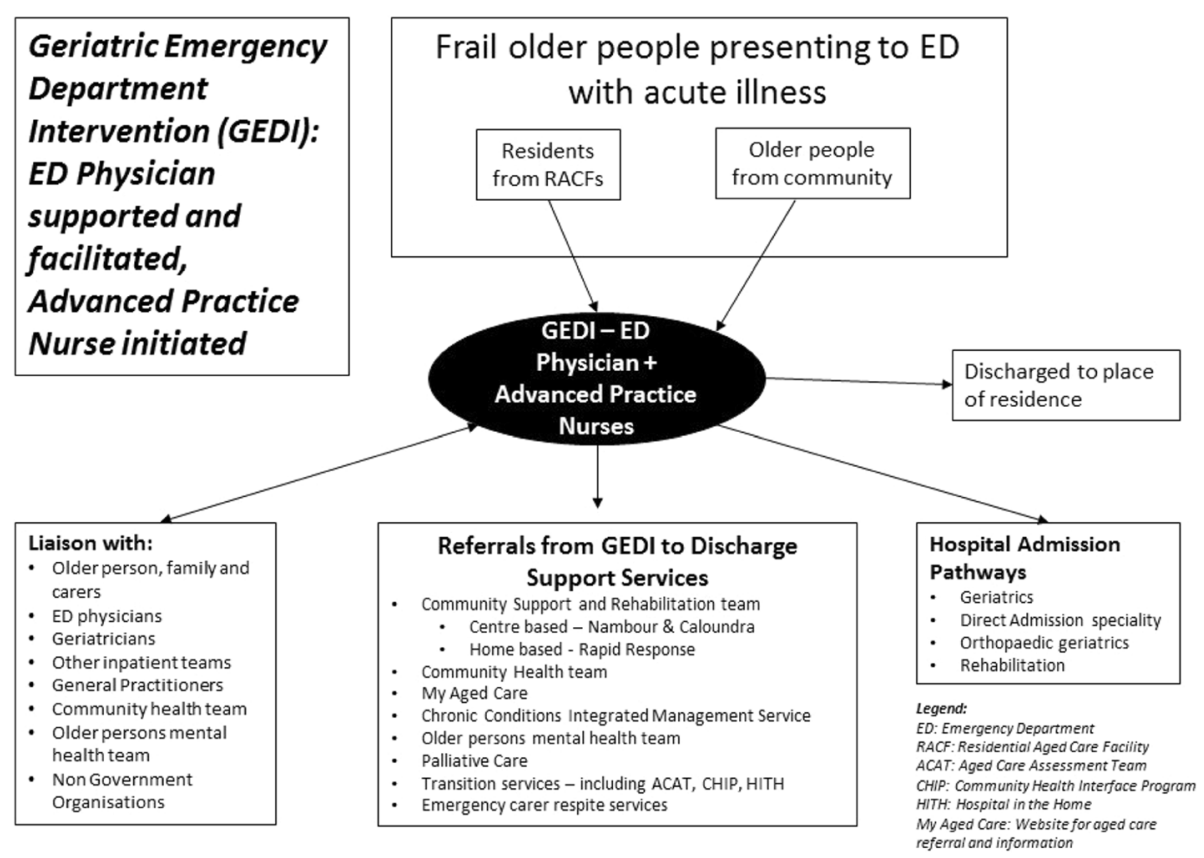

Fig. 1 GEDI model of assessment and interaction with support services

assessment. A targeted assessment reduces the length of time required while still identifying deficits and the available resources needed to fulfil the requisites found. The GEDI assessment of the older person involves utilising a variety of tools to assess for recent changes in cognition, function and risk of injury. The GEDI nurse will where possible, assess for changes over time and will refer to information from a range of sources including, but not limited to, the patient, the medical records, the PCP, the patient's family members and other health and social care professionals. Communication with the ED Physician and Geriatrician when necessary, assists in building on the findings of the assessment.

The Confusion Assessment Method (CAM) is utilised by GEDI nurses to determine the presence of cognitive impairment, particularly delirium in older adults. Delirium is a common symptom in older adults presenting to the ED and diagnosis is reported to be missed by Emergency Physicians in between 56 and $76 \%$ of cases [31, 32]. The CAM is validated for use in ward areas, post-operative recovery [33], intensive care [34] and is one of the few geriatric tools validated for use in the ED [35]. A limitation of the CAM is that it is for use throughout the whole hospital rather than being a tool specifically for use in the ED and the particular circumstances of acutely unwell older adults at first presentation to the ED. One other tool the GEDI team use is the interRAI ED screener (Health Etraining International Ltd.) for all non-RACF elderly presentations to the ED, a new risk assessment tool currently under evaluation.
Data from assessments performed by the primary nurse in ED are also used by the GEDI team in determining health status, functional decline and frailty in older people. The Adult Deterioration Detection System (ADDS) score [36] is calculated using the ADDS charting tool and used as an early warning of deterioration. Health professionals are reported to agree strongly on the ease of use of the ADDS chart and subsequent risk scoring system [37]. Additional data collected by the primary nurse in the ED such as falls risk and pain assessment are also considered. The GEDI team focus on adding value to the information that is already available for each elderly person in the ED, leaving any other non-urgent activity to be done in appropriate areas of the hospital, the ward or via community services.

\section{Similarities and Differences to other interventions in the ED for acutely unwell older adults}

Systematic reviews of interventions in EDs for older people report the most successful interventions are delivered by multidisciplinary teams and use comprehensive geriatric assessment (CGA) $[15,16]$. In some areas of Australia, specialist nurses operate as part of an Aged Care Services Emergency Team (ASET), a State Government initiative providing CGA in the $\mathrm{ED}$, community referral, fast-track assessment, education to ED staff, and initiation of programs to improve ED outcomes [38]. The GEDI team utilises these interventions as part of their care of the older person focusing on targeted assessments as outlined earlier. However, differences lie 
in health professional collaboration, with assessments completed by the allied health team and the ED primary nurse, such as falls risk and pain assessment, being included in the GEDI assessment. This improves the efficiency of the collation of information and assists the medical team in decision making about the care and supported discharge of the older person. Some areas in South Eastern Australia have included a "third door" access to the ED for older people to provide sub-acute services for older people bypassing the ED [39]. These "Healthcare for Older Persons Earlier" (HOPE) wards do not have the same $4 \mathrm{~h}$ targets as ED, similar to short stay units, often in or next to the ED, utilised in many hospitals for ED presentations needing longer than $4 \mathrm{~h}$ but not a full admission to hospital [40]. Concerns have been expressed that patients presenting to EDs are being admitted to these types of wards to bypass NEAT, but without the necessary addition of service delivery. An increase in admissions to these areas from ED has been seen post 2010 [41].

Further to these models, the Aged Care Emergency (ACE) service provides evidence based resources, telephone support by an ED advanced practice nurse, education and proactive case management aligned with pre-established goals of care [42]. Similarly, GEDI have a dedicated telephone line that staff from RACFs, or primary care areas such as PHPs, can use to contact the GEDI team. However, the focus of the telephone support is communication and provision of supporting information about the older person should they be in the process of transfer to the ED. This ensures that the PHP remains central to the care of the older person and any changes in care, to enhance recovery from an acute illness, are directly discussed. Another service providing outreach telephone support is CARE-PACT which provides hospital-based telephone referral by a clinical nurse, to any of four services: 1 . Hospital ED based treatment (for acute conditions that cannot be treated within the RACF), 2. Referral to existing primary care resources 3 . Consultation with the PHP and 4. Mobile assessment and treatment resources [43]. However, this model only caters for older people from RACFs and research evaluation of CAREPACT is not published in the literature at the time of writing. HINH provides an outreach service delivering acute care nursing support services, medication and equipment to the RACF nurse [13] to prevent admission to hospital and fast-track discharge back to the RACF for appropriate elderly people thereby avoiding admission. GEDI does not provide mobile assessment and treatment resources as the current focus is on admission avoidance. Interestingly, in the review of the ACE model, only hospital admission avoidance could be demonstrated [42].
GEDI is unique in its design relating to the key personnel who operate as part of the GEDI team. A passionate ED physician saw the need for improving the care for older people presenting to ED and streamlining their care to avoid the complications of long wait times. This role has remained central and integral to the GEDI model in creating acceptance and driving change in the ED to embed this model of care as part of business as usual. Finding the right mix of advanced practice nurses with education, skills and experience in care of geriatric populations to ensure the recognition of symptoms particular to older persons and coordination with appropriate services for discharge support is critical. Together, these professionals target the frail older persons presenting to the ED to assist in navigating their journey through the health system safely and in a timely manner.

\section{Conclusion}

This commentary has presented the GEDI model for care for older people presenting to ED. Research underpinning the interventions and assessments used by the GEDI team demonstrates the evidence-based foundation of this innovation. GEDI aims to improve the care of older people while facilitating admission avoidance where appropriate via referral to existing community services. This enables care for older people to be provided at a primary care level in the persons' place of residence, be that the community or RACF and therefore avoid complications of hospital transfer and admission when other pathways are available.

\section{Abbreviations}

ACD: Advance Care Plan_legal document outlining the health care to be undertaken should the owner not be able to communicate that care to health professionals; ACE: Aged Care Emergency - a model of care for older people used in some hospitals in Australia; ADDS: Adult Deterioration Detection System - a scoring system based on observations taken in emergency such as pulse rates, respiratory rate, temperature, blood pressure to determine risk of deterioration; ASET: Aged Care Services Emergency Team-a model of care for older people in some hospitals across New South Wales, Australia; CAM: Confusion Assessment method-a tool for measuring cognitive impairment in adults; CGA: Comprehensive Geriatric Assessment-a detailed assessment for older people to determine functional capacity; ED: Emergency department - area in a hospital for emergency healthcare; GEDI: Geriatric Emergency Department Intervention - the model of care described in this report; $\mathrm{HINH}$ : Hospital in the Nursing Home-discharged from hospital to the residential aged care facility or nursing home under the care of health professionals who visit the facility to provide care; HITH: Hospital in The Home-discharged from hospital to place of residence other than a residential aged care facility or nursing home, under the care of health professionals who visit to provide care; HOPE: Healthcare Older People Earlier - a model of care for older people used in some hospitals in Australia; NEAT: National Emergency Access Target - a targeted time frame to assess and care for people in the Emergency Departments; PHP: Primary Healthcare Physician — the health professional responsible for primary care of a person, in Australia this role is generally carried out by a General Practitioner; RACF: Residential Aged Care facilities_facility for providing long-term care for older adults, a nursing home 


\section{Acknowledgements}

The authors would like to acknowledge the contribution of Ms Colleen Johnston to final proofing of this article.

\section{Funding}

The evaluation of this model of care is part of larger project funded by the Department of Social Services, Australian Government: Aged Care Service Improvement and Healthy Ageing Grants.

\section{Availability of data and materials}

Not applicable.

\section{Authors' contributions}

$A C, E M, A T, M W$ have made substantial contributions to conception and design, or acquisition of data; AC drafted the manuscript; AC, EM, AT, MW revised manuscript critically for important intellectual content; $A C, E M, A T$, MW have given final approval of the version to be published and agree to be accountable for all aspects of the work in ensuring that questions related to the accuracy or integrity of any part of the work are appropriately investigated and resolved. All authors read and approved the final manuscript.

\section{Competing interests}

The authors declare that they have no competing interests.

\section{Consent for publication}

All authors have consented to this publication.

\section{Ethics approval and consent to participate}

Not applicable.

\section{Author details}

'University of the Sunshine Coast, 90 Sippy Downs Drive, Sippy Downs, Qld 4556, Australia. ${ }^{2}$ Sunshine Coast Hospital and Health Service, Nambour General Hospital, Hospital Road, Nambour, Qld 4560, Australia.

Received: 24 September 2016 Accepted: 26 October 2016

\section{Published online: 09 November 2016}

\section{References}

1. Gray LC, Peel NM, Costa AP, Burkett E, Dey AB, Jonsson PV, et al. Profiles of older patients in the emergency department: findings from the interRAl Multinational Emergency Department Study. Ann Emerg Med. 2013;62(5):467-74.

2. Freed G, Gafforini S, Carson N. Age-related variation in primary care type presentations to emergency departments. Aust Fam Physician. 2015;44(8):584-8.

3. Kamali M, Jain A, Jain M, Schneider S. Why do patients with minor complaints prefer emergency departments over primary care physicians? Ann Emerg Med. 2011;58(4s):S235.

4. Lowthian J, Curtis A, Stoelwinder J, McNeil J, Cameron P. Emergency demand and repeat attendances by older patients. Intern Med J. 2013;43(5):554-60.

5. Arendts G, Reibel T, Codde J, Frankel J. Can transfers from residential aged care facilities to the emergency department be avoided through improved primary care services? Data from qualitative interviews. Australas J Ageing. 2010;29(2):61-5.

6. Codde J, Arendts G, Frankel J, Ivey M, Reibel T, Bowen S, et al. Transfers from residential aged care facilities to the emergency department are reduced through improved primary care services: an intervention study. Australas J Ageing. 2010;29(4):150-4.

7. Morphet J, Innes K, Griffiths DL, Crawford K, Williams A. Resident transfers from aged care facilities to emergency departments: can they be avoided? Emerg Med Australas. 2015;27(5):412-8.

8. Dwyer R, Gabbe B, Stoelwinder JU, Lowthian J. A systematic review of outcomes following emergency transfer to hospital for residents of aged care facilities. Age Ageing. 2014;43(6):759-66.

9. Aldeen A, Courtney D, Lindquist L, Dresden S, Gravenor S. Geriatric Emergency Department Innovations: preliminary data for the geriatric nurse liaison model. J Am Geriatr Soc. 2014;62:1781-5.

10. Arendts $G$, Howard $K$. The interface between residential aged care and the emergency department: a systematic review. Age Ageing. 2010;39(3):306-12.

11. Christian R, Baker K. Effectiveness of nurse practitioners in nursing homes: a systematic review. JBI Library Syst Rev. 2009;7(30):1359-78.
12. Conway J, Dilworth S, Hullick C, Hewitt J, Turner C, Higgins I. A multiorganisation aged care emergency service for acute care management of older residents in aged care facilities. Aust Health Rev. 2015;39(5):514-6.

13. Crilly J, Chaboyer W, Wallis M, Thalib L, Polit D. An outcomes evaluation of an Australian Hospital in the Nursing Home admission avoidance programme. J Clin Nurs. 2011;20(7-8):1178-87.

14. Donald F, Martin-Misener R, Carter N, Donald EE, Kaasalainen S, WicksonGriffiths A, et al. A systematic review of the effectiveness of advanced practice nurses in long-term care. J Adv Nurs. 2013;69(10):2148-61.

15. Hastings $\mathrm{SN}$, Heflin MT. A systematic review of interventions to improve outcomes for elders discharged from the emergency department. Acad Emerg Med. 2005;12(10):978-86.

16. McCusker J, Verdon J. Do geriatric interventions reduce emergency department visits? A systematic review. J Gerontol A Biol Sci Med Sci. 2006;61 (1):53-62.

17. Silvester KM, Mohammed MA, Harriman P, Girolami A, Downes TW. Timely care for frail older people referred to hospital improves efficiency and reduces mortality without the need for extra resources. Age Ageing. 2014;43(4):472-7.

18. Wright PN, Tan G, liffe $S$, Lee $D$. The impact of a new emergency admission avoidance system for older people on length of stay and same-day discharges. Age Ageing. 2014;43(1):116-21.

19. Conroy SP, Ansari K, Williams M, Laithwaite E, Teasdale B, Dawson J, et al. A controlled evaluation of comprehensive geriatric assessment in the emergency department: the 'Emergency Frailty Unit'. Age Ageing. 2014; 43(1):109-14.

20. Fan L, Xiang-Yu H, Zhao J, Sun J, Dingle K, Purtill $R$, et al. Hospital in the Nursing Home program reduces emergency department presentations and hospital admissions from residential aged care facilities in Queensland, Australia: a quasi-experimental study. BMC Health Serv Res. 2016;16:46.

21. Shepperd S, Doll H, Broad J, Gladman J, lliffe S, Langhorne P, et al. Hospital at home early discharge. Cochrane Database of Systematic Reviews: John Wiley \& Sons, Ltd; 2009; (1):CD000356. doi: 10.1002/14651858.CD000356.pub3

22. Australian Government Department of Health and Ageing. Expert panel review of elective surgery and Emergency Access Targets under the National Partnership Agreement on improving Public Hospital Services: Report to the Council of Australian Governments. Canberra: Commonwealth of Australia; 2011.

23. Street M, Marriott JR, Livingston PM. Emergency department access targets and the older patient: a retrospective cohort study of emergency department presentations by people living in residential aged care facilities. Australas Emerg Nurs J. 2012;15(4):211-8.

24. Lowthian JA, Curtis AJ, Folley DJ, Stoelwinder JU, McNeil JJ, Cameron PA. Demand at the emergency department front door: 10-year trends in presentations. Med J Aust. 2012;196(2):128-32.

25. Australasian College for Emergency Medicine. Guidelines for the Implementation of the Australasian Triage Scale. Melbourne, VIC: 2013 Report No.: G24, Version V04. http://www.acem.org.au/getattachment/ 4320524e-ad60-4e7c-a96d-bdf90cd7966c/G24-Implementation-oftheAustralasian-Triage-Scal.aspx.

26. Ong TJ, Ariathianto Y, Sinnappu R, Lim WK. Lower rates of appropriate initial diagnosis in older emergency department patients associated with hospital length of stay. Australas J Ageing. 2014;34(2):121-6.

27. Arendts G, Dickson C, Howard K, Quine S. Transfer from residential aged care to emergency departments: an analysis of patient outcomes. Intern Med J. 2012:42(1):75-82.

28. Braithwaite J, Wears R, Hollnagel E. Resilient health care: turning patient safety on its head. International J Qual Health Care. 2015;27(5):418-20.

29. Ellis G, Whitehead MA, Robinson D, O'Neill D, Langhorne P. Comprehensive geriatric assessment for older adults admitted to hospital: meta-analysis of randomised controlled trials. BMJ. 2011;343:d6553.

30. Ellis $\mathrm{G}$, Marshall T, Ritchie C. Comprehensive geriatric assessment in the emergency department. Clin Interv Aging. 2014;9:2033-43.

31. Hustey FM, Meldon SW. The prevalence and documentation of impaired mental status in elderly emergency department patients. Ann Emerg Med. 2002;39:248-53.

32. Han JH, Zimmerman EE, Cutler N, Schnelle J, Morandi A, Dittus RS, et al. Delirium in Older Emergency Department Patients: recognition, risk factors, and psychomotor subtypes. Acad Emerg Med. 2009;16:193-200.

33. Rolfson DB, McElhaney JE, Jhangri GS, Rockwood K. Validity of the confusion assessment method in detecting postoperative delirium in the elderly. Int Psychogeriatr. 1999;11(4):431-8. 
34. Ely E, Inouye SK, Bernard GR, et al. Delirium in mechanically ventilated patients: Validity and reliability of the confusion assessment method for the intensive care unit (cam-icu). JAMA. 2001;286(21):2703-10.

35. Shi Q, Warren L, Saposnik G, MacDermid JC. Confusion assessment method: a systematic review and meta-analysis of diagnostic accuracy. Neuropsychiatr Dis Treat. 2013;9:1359-70.

36. Preece M, Horswill M, Hill A, Watson M. The development of the Adult Deterioration Detection System (ADDS) chart. Sydney. New South Wales: Australian Commission on Safety and Quality in Health Care; 2010.

37. Elliott $D$, Allen E, McKinley S, Perry L, Duffield C, Fry M, et al. User acceptance of observation and response charts with a track and trigger system: a multisite staff survey. J Clin Nurs. 2016;25(15-16):2211-22.

38. Shanley C, Sutherland A, Tumeth R, Stott K, Whitmore E. Caring for the older person in the emergency department: the ASET program and the role of the ASET clinical nurse consultant in South Western Sydney, Australia. J Emerg Nurs. 2009;35(2):129-33.

39. Geriatric Medicine Department. Healthcare for Older Persons Earlier (HOPE) Strategy. Westmead Hospital, Sydney West Area Health Service. 2008. Retrieved fromhttp://www.aci.health.nsw.gov.au/networks/acutecare-taskforce/mau-nsw/2/hope-westmead.pdf.

40. Tse R, Thompson N, Moscova M, Sindhusake D, Shetty A, Young N. Do delays in radiology lead to breaches in the 4-hour rule? Clin Radiol. 2016;71(6):523-31.

41. Mason S, Nicholl J, Locker TE. Four hour emergency target. Targets still lead care in emergency departments. BMJ. 2010;341:C3579.

42. Hullick C, Conway J, Higgins I, Hewiitt J, Dilworth S, Holiday E, et al. Emergency department transfers and hospital admissions from residential aged care facilities: a controlled pre-post design study. BMC Geriatr. 2016;16(106):1-10

43. Burkett E, Scott I. CARE-PACT: A new paradigm of care for acutely unwell. residents in aged care facilities. Aust Fam Physician. 2015;44(4):204-9.

\section{Submit your next manuscript to BioMed Central and we will help you at every step:}

- We accept pre-submission inquiries

- Our selector tool helps you to find the most relevant journal

- We provide round the clock customer support

- Convenient online submission

- Thorough peer review

- Inclusion in PubMed and all major indexing services

- Maximum visibility for your research

Submit your manuscript at www.biomedcentral.com/submit

) Biomed Central 